\title{
A LOS 90 AÑOS DE LA REVOLUCIÓN DE 1930 EN BRASIL. LA CONSTRUCCIÓN SOCIAL DEL AUTORITARISMO BRASILEÑO
}

\author{
90 years after the 1930 revolution in Brazil. \\ The social construction of Brazilian authoritarianism \\ Carlos Sixirei Paredes \\ Universidad de Vigo
}

Recibido: 01/06/20

Aceptado: 15/06/20

\begin{abstract}
Resumen
Los acontecimientos políticos que se desatan en Brasil a partir de 1930 marcan el origen de un nuevo modelo de estado modernizador e intervencionista al mismo tiempo que otro concepto de nación más inclusivo que el dominante hasta ese ańo permite incorporar al juego político a un creciente número de sectores sociales que estaban marginados.
\end{abstract}

Palabras clave

Revolución, Brasil, militarismo, autoritarismo, Vargas, oligarquía.

\begin{abstract}
Brazil after 1930 mark the origin of a new model of modernizing and interventionist State at the same time as another concept of Nation more inclusive than the dominant one until that year allows a growing number to be incorporated into the political game from social sectors were marginalized.
\end{abstract}

Key words

Revolution, Brazil, militarism, authoritarianism, Vargas, oligarchy. 


\section{El escenario previo}

La Revolución de 1930 en Brasil ha provocado una enorme corriente de estudios, investigaciones y debates. Para comenzar, el propio uso del término "revolución" ha sido discutido en relación a lo apropiado de su uso para calificar los hechos políticos que ese año se sucedieron. Pero para explicarnos que ocurrió en todos los frentes tenemos que remontarnos a un año antes, a 1929, y, en concreto al mes de octubre, cuando se produce el crack de la bolsa neoyorkina arrastrando en su caída a toda la economía capitalista.

Podríamos decir como Nassim Talev, que la crisis del 29 fue una suerte de cisne negro. Pero ¿que entendemos por esa expresión? Según Talev un cisne negro es un acontecimiento de gran impacto y cuya predictibilidad es retrospectiva y no prospectiva. Es decir, en román paladino, que a toro pasado todo el mundo lo veía venir. Pero la realidad es que nadie lo vio.

¿Fue realmente así?

Como escribió irónicamente Pablo González Casanova con respecto a México, Brasil recibió la crisis del 29 con los brazos abiertos y los ojos cerrados. Ciertamente yo soy partidario más partidario del análisis regional de las consecuencias de la crisis que de entrar en visiones pormenorizados de puertas adentro, es decir, de carácter nacional ${ }^{1}$, pero al estudiar un fenómeno político concreto que tiene como trasfondo un acontecimiento que afecta al continente en su conjunto (por referirme solo a América), no cabe duda de que se deben considerar matices locales que dan una identidad propia a las diversas respuestas nacionales.

La interpretación de la crisis del 29 en lo que se refiere a Iberoamérica se ha movido en los siguientes parámetros:

- La concepción tradicional defendida por Raúl Prebisch y los teóricos de la CEPAL. La crisis se origina en los países centrales y de éstos es exportada a los países periféricos a través de: Caída de los precios internacionales de las materias primas, caída de las exportaciones hacia los limitados mercados tradicionales y cierre del crédito. Al haberse adoptado el modelo de crecimiento hacia afuera en los países dependientes y al basarse este modelo en las exportaciones de materias primas no transformadas cuyos precios en el mercado internacional nunca fueron determinados por los productores, los países agroexportadores o mineroexportadores resultaron muy frágiles ante la crisis, sin capacidad de respuesta en el corto y medio plazo, y enormemente afectados en sus ingresos fiscales. La respuesta fue tratar de reconstruir las antiguas dependencias

1 Sobre una visión continental de los efectos de la crisis del 29 en Iberoamérica ver Angus Maddison (1988). 
para garantizarse mercados $y$, donde se pudo y forzados por las circunstancias, favorecer una ISI (industrialización por sustitución de importaciones).

- La concepción estructuralista que tiene como principal representante a Celso Furtado que guarda bastantes puntos en común con la anterior pero añade el cambio estructural que se produce entre las economías iberoamericanas anteriores a 1930 y el modelo desarrollista que emerge con mayor o menor fuerza en todos los países de la región a partir de 1945. Los años comprendidos entre 1930 y 1945 se corresponderían a un periodo de transición entre ambos modelos.

¿Y que estaba ocurriendo en Brasil? Los años 20 resultan una década extremadamente conflictiva. Las costuras del viejo traje que había creado la oligarquía agrario-exportadora y, singularmente, la oligarquía cafetera, estaban rompiendo por todos lados. El Brasil de 1920 ya no cabe en el patrón del Brasil de 1900. Ha habido demasiados cambios y cambios no previstos: La emergencia de una clase obrera, la aparición de las clases medias urbanas, la transformación económica de algunas zonas del país, la crisis de las viejas alianzas oligárquicas, el papel creciente que las FFAA juegan en la política, los cambios culturales introducidos por los inmigrantes... todos estos ingredientes acabarían por configurar un cóctel explosivo que estalla en 1930

En términos económicos los años 20 atraviesan dos fases: La primera va de 1919 a 1925, es un periodo de incertidumbres, de altos y bajos y de crisis económica debido tanto a razones políticas (sucesivas revueltas militares desde 1922) como a la dificultad de negociar créditos en los mercados de Londres y Nueva York y a la caída de los precios del café en el bienio 1924-25 lo que llevó a una fuerte recesión. La segunda, de 1926 a 1929, constituye una etapa de euforia económica al aumentar los precios de la rubiácea y al mejorar los flujos de capital, además de conseguirse la estabilización de la moneda tras el restablecimiento del patrón oro. En realidad en esta fase había ya anuncios evidentes de que se cernía una tormenta en el horizonte aunque nadie fuese capaz de adivinar ni su intensidad ni su naturaleza, y entre estos anuncios figuraban las cosechas gigantes de café de 1927 y 1929 que amenazaban los precios internacionales al poner en el mercado una sobreproducción, y el deterioro del mercado internacional de capitales que ya era visible desde 1928.

Justamente es en ese periodo de euforia cuando se hace cargo del ministerio de Hacienda por breve tiempo el que va a ser el personaje central de la revolución de 1930: Getúlio Vargas.

Vargas era, desde 1923, un gris diputado federal representante del Partido Libertador Riograndense que, a pesar de ser el portavoz de la bancada gaúcha ${ }^{2}$, no

2 A los de Rio Grande do Sul se les conoce en Brasil como gaúchos. 
había tenido mucho lucimiento en una cámara en la que se enfrentaban a diario los mejores picos de oro del Brasil. Pero fue precisamente ese grisáceo perfil, unido a su lealtad al candidato vencedor de la elecciones presidenciales de 1926, el carioca que ejercía de paulista Washington Luis Pereira de Sousa, lo que le llevaría a ocupar en el primer gabinete del recién posesionado Presidente de la República, la cartera de Hacienda. El nombramiento parecía una broma. Vargas había renunciado, no hacía mucho tiempo, a ocupar un puesto en la Comisión de Finanzas de la Cámara de Diputados alegando su total desconocimiento de los asuntos económicos. Pero Washington Luis no necesitaba un hacendista al frente del ministerio, necesitaba un hombre fiel y leal al margen de que supiera o no algo sobre el tema. Vargas sería una simple correa de transmisión de la política presidencial. No era el único en aquel gabinete de inexpertos en donde, salvo las carteras militares, las demás estaban cubiertas por hombres que no entendían nada del área de su competencia. Contaba, por ejemplo, el embajador británico que el ministro de Agricultura, oftalmólogo de profesión, no servía ni para plantar coles en el jardín de su casa ${ }^{3}$.

El breve tiempo que Getúlio ocupó el ministerio lo hizo, sin embargo, bien. En economía soplaba el viento a favor y las líneas básicas de la política económica las marcaba el presidente. El ministro no tenía más que aplicarlas. Fue, en ese sentido, un excelente recadero. Trece meses después Vargas dejaba la cartera para presentarse como candidato a la presidencia de Rio Grande do Sul, su estado natal. Pero en esos trece meses, además de dejar memoria de una buena gestión, tejió una red de amistades que le serían muy útiles cuando se planteara otros objetivos, entre ellos el periodista y empresario Assis Chateaubriand, dueño del muy influyente O Jornal, y la red clientelar de coterráneos a los que en su momento colocó al frente del Banco do Brasil, el gabinete ministerial, las principales direcciones generales etc. Cuando, en medio del aplauso general, (bastante inmerecido, por lo demás) abandona el ministerio su agenda de amigos y clientes se había considerablemente reforzado.

\section{La crisis de 1929 en Brasil}

En el momento de presentarse la crisis económica en Brasil, el país cuenta con 33 millones de habitantes, un $125 \%$ más que cuando 40 años antes se había proclamado la Republica. El escenario había cambiado y las circunstancias no eran las mismas, pero el sistema político creado continuaba incólume, aunque ya hacía tiempo que le estaban serrando el suelo. El derrumbe económico seria el golpe final.

3 Ver C. Sixirei (2019), pg. 702. 
Brasil era el país del continente con menor coeficiente de abertura al exterior. Su comercio internacional (importaciones + exportaciones) representaba tan solo el 38\% del PIB frente al 60\% de Argentina, el 57\% de Chile o el 48\% de México. Este reducido grado de apertura no hizo al país menos vulnerable a los choques externos lo que no deja de resultar paradójico. Para entenderlo debemos acudir, por una parte, a la elevada concentración de las exportaciones en un producto y a la volatilidad de los movimientos de capitales muy correlacionados perversamente con los términos de intercambio de Brasil a lo que hay que añadir las deficiencias internas en factores importantes como la calidad del capital humano, la productividad, el funcionamiento de las instituciones o la mentalidad del capitalismo local muy dependiente de los países centrales. Probablemente estos factores no ayuden a explicar en su totalidad las razones del hundimiento de la economía nacional, pero sin duda lo vuelven inteligible en buena parte.

Sin embargo, y a pesar de la extrema dependencia del comercio exportador brasileño con respecto al café ( $y$, por lo tanto de buena parte de los ingresos de aduana, uno de los principales rubros, si no el más importante de la recaudación fiscal de la República), el país tenía una de las economías más diversificadas del continente. Ciertamente Brasil en 1929 era un país predominantemente rural con una economía fundamentalmente de base agraria. Pero eso les ocurría a todos sus vecinos. Con la excepción de Argentina en donde la presencia urbana era más importante, en los demás países seguía predominando la población campesina. Veamos el siguiente cuadro para 1929:

\begin{tabular}{|c|c|c|}
\hline \multicolumn{3}{|c|}{ Cuadro } \\
\hline PAIS POB. & POB. URBANA\% & POB. RURAL\% \\
\hline Argentina & 57,1 & 42,9 \\
\hline Uruguay $^{4}$ & 32 & 68 \\
\hline Brasil & 15 & 85 \\
\hline Cuba & 38 & 62 \\
\hline México & 30 & 70 \\
\hline Colombia & 33 & $67^{5}$ \\
\hline
\end{tabular}

4 El caso de Uruguay es realmente complicado. No se hicieron censos de población total entre 1908 y 1963. En los estudios sobre distribución de la población no se hace discriminación entre población urbana y población rural sino entre Montevideo e Interior. Esto se debe a que hasta la década de los 30 en que comienzan a desarrollarse zonas periurbanas de Montevideo en el departamento de Canelones, próximo a la capital, las capitales departamentales, debido a su muy limitado desarrollo, se consideraban más áreas rururbanas que propiamente urbanas.

5 Se trata en la mayor parte de los casos de cálculos aproximados pues en los años 20 no hay censos en esos países y los más próximos son de 1938. Las cifras indicadas se hicieron a partir 
Esta diversificación de la que hablamos es tanto regional como sectorial aunque sin un aumento significativo de la participación en el PIB. En 1930 la agricultura aún respondía por el 35,8\% del total contra el 14,8\% de la industria y el 49,4\% de los servicios. En Argentina, la agricultura y la ganadería representaban ese mismo año el 17, 76\% del PIB nacional mientras que la industria suponía el 22,4\%. El Censo de 1920 reveló la existencia de 13.336 establecimientos fabriles en los que trabajaban sobre 276.000 obreros/as con predominio absoluto de la producción textil y alimentaria las cuales sumadas eran el 64,5\% del conjunto de la industria. En cuanto a la distribución industrial, el estado de São Paulo era responsable por el 33,1\% del valor de la producción y del 30,6\% del empleo fabril.

Brasil contaba en 1930 con una industria textil moderna, importante incluso en términos internacionales. Era la mayor de Iberoamérica y comparable a la que por entonces tenía China. El número de fábricas textiles pasó de 242 en 1921 a 354 en 1927 creciendo el número de husos en un 59\% y el de telares en un 32\%. Solo en la gama más alta de los tejidos, y gracias a que la fortaleza de la moneda brasileña favorecía las importaciones, podían los productores extranjeros competir con la industria local. En 1929 el 92\% de las necesidades de consumo de textiles del mercado brasileño era cubierto por la industria nacional.

Después de 1914 se establecieron nuevos sectores industriales en Brasil aunque nunca se llegó a la fabricación de productos sofisticados, no tanto por falta de interés de los empresarios como por las políticas cambiarias y tarifarias que cabe definir en los años 20 como simplemente erráticas. Por otra parte, los sucesivos gobiernos, todos ellos hijos del sistema establecido por la oligarquía agraria, eran poco proclives tanto al proteccionismo como a una política de apoyo a la industria a la que seguían viendo como algo artificial convencidos, como estaban, de que la economía brasileña debería descansar casi en exclusiva sobre la producción agrícola. Por otra parte las rentas de aduana seguían configurando el grueso de la recaudación fiscal. En 1929 respondían por el 38\% del total de los ingresos federales contra el 19\% que suministraba el impuesto al consumo.

Frente a las debilidades de la industria aparecía el café como el principal sostén de la economía. Pero ese sostén estaba en manos de unos pocos. En 1930 el área territorial en manos de particulares ascendía a 175.000.000 de Has. de las cuales el $28 \%$ lo constituían bosques y selvas con lo que quedaban para el cultivo y la

de los datos proporcionados por las siguientes obras: José Antonio Ocampo (2000): Historia económica de Colombia, Bogotá TM Editores, pg. 244; Orlando Ferreres (2005) Dos siglos de economía argentina, Buenos Aires, Fundación Norte y Sur, pg. 127; Carlos Sixirei (2019); Consuelo Naranjo Orovio (2009) Historia de Cuba, Madrid, CSIC, pg. 51; Instituto Nacional de Estadística (2012) Censos 1852-2011, Montevideo: Claudia Montserrat Martínez Stone: (2001) Censo General de la República, Antecedentes Históricos, México, pg. 3. 
ganadería 126.000.000. De las 175.000.000 que constituían la propiedad agraria, 135.000.000 estaban en manos de 64.000 propietarios mientras que las 40.000 .000 restantes pertenecían a $600.000^{6}$. Así que en un país de base agrícola y de enorme extensión el $89 \%$ de los brasileños no poseía ni un metro cuadrado. Esta concentración de tierra en pocas manos se manifestaba en la existencia de latifundios inmensos. Tal era el caso de la firma Costa\&Ferreira compuesta por dos socios que poseía en Pará una propiedad cuya superficie equivalía a la de Gran Bretaña e Irlanda juntas. Había otras en ese estado y en Mato Grosso que eran tan grandes como Portugal.

Y si en vez de una visión global del país acercamos la mirada para ver lo que ocurría en los diversos estados de la Unión los resultados eran aún peores. En Minas Gerais solo era propietario agrario el 7,3\% de los habitantes mientras que el 69,3\% de la propiedad estaba en manos de 503 familias. En Pernambuco toda el área en manos de particulares pertenecía al 8\% de la población. Incluso en los estados del sur, de mayor desarrollo económico y social, había latifundios enormes. Antônio Prado en São Paulo era el mayor cafeicultor del mundo poseyendo en sus diversas propiedades más de 7 millones de cafetos repartidos por sus 33 haciendas en donde trabajaban 8.000 colonos.

Sin embargo la propiedad de la tierra en sí misma no representaba poder político. No era tan importante lo que se tenía como lo que se cultivaba. Si hasta 1870 la aristocracia imperial, que monopolizaba el Estado en su beneficio, estaba integrada fundamentalmente por los propietarios de los ingenios azucareros y de las grandes fincas ganaderas nordestinas, desde ese año el ejercicio del poder fue trasladándose progresivamente a manos de la oligarquía cafetera del centro-sur, fundamentalmente de la que habitaba en São Paulo y Minas Gerais. Ambas establecen un pacto para monopolizar la presidencia de la recién nacida República concretado a partir del primer gobierno civilista que se establece en 1894 bajo la presidencia de Prudente de Moraes. Con su sucesor Campos Salles, se inaugura la llamada política de los estados, consistente en una alianza entre los estados más importantes para controlar la República y dar estabilidad al gobierno federal a cambio de que este no se inmiscuya en su política interna. El núcleo duro de este acuerdo es la alianza del café con leche, como gráficamente fue bautizada en su tiempo, y que otorgaba casi en monopolio la presidencia de la República a un mineiro o a un paulista debiendo, en teoría, alternarse en el ejercicio de la jefatura del estado. De hecho entre 1898 y 1930 hay un presidente nordestino, otro carioca (que llegó a la presidencia de rebote) y otro riograndense frente a 4 mineiros y 4

6 V. C. Sixirei (1988) Vol. I, pg. 22. 
paulistas más el último presidente anterior a 1930, Washington Luis que, aunque nacido en el estado de Rio de Janeiro, fungió de paulista toda su vida.

Así que la política en la Primera República era un ejercicio practicado en exclusiva por las oligarquías, y no siquiera por todas. De hecho podríamos hablar de un círculo central formado por los dos estados política y demográficamente hegemónicos, una primera periferia en la que entrarían los dos estados nordestinos más importantes (Bahía y Pernambuco) más Rio Grande do Sul y una tercera periferia formada por todos los demás incluyendo el estado de Guanabara donde se asentaba la capital del país y que, en su conjunto, pintaban más bien poco en la política nacional. Las oligarquías locales eran meras correas de transmisión de las decisiones que en Rio de Janeiro tomaban los grupos dominantes los cuales, a cambio, no intervenían en los frecuentes conflictos que enfrentaban a las diversas fracciones oligárquicas en su lucha por el poder municipal y estatal. A menos, claro está, que peligrara la hegemonía de la fracción aliada local.

Podríamos decir, sin exagerar, que la economía y el poder político de Brasil estaban en los años veinte en manos de no más de 2.000 familias entre empresarios, banqueros, grandes comerciantes y propietarios agrarios. Pero con notables diferencias entre ellos aunque de momento nadie discutía la hegemonía del grupo agrario-exportador.

\section{Los componentes sociales de la crisis de $\mathbf{1 9 3 0}$}

Y ahí venía el primer problema. Porque este grupo se apoyaba en el papel que representaba en las exportaciones. Pero el comercio de exportación de Brasil, como ya quedó indicado, no era algo de tan extrema importancia en un país que era el más cerrado de Iberoamérica en términos de intercambios con el exterior.

La historia económica de Brasil se define por ciclos, algunos de larga duración y otros muy efímeros: El ciclo del azúcar ligado a la expansión de la esclavitud, el ciclo del oro y el ciclo de los diamantes en la etapa colonial; el ciclo del café vinculado a la inmigración, el ciclo del cacao y el ciclo del caucho en la etapa republicana ${ }^{7}$. Todos ellos tuvieron, sobre todo, importancia local. Mientras que el azúcar garantizó el poder nordestino en los años de la colonia y parte de la etapa monárquica, el café concedió la primacía en todos los órdenes al estado de São Paulo. Pero ni la sacarocracia ejercía influencia sobre el centro-sur o el norte y el oeste, ni el café

7 La etapa imperial está a caballo entre la economía del azúcar, cuya decadencia se completa en ese periodo junto a la crisis del sistema esclavista, y el comienzo de la hegemonía cafetera acompañada del auge migratorio. 
era capaz de influir sobre la política del nordeste o de Rio Grande do Sul. En todo este esquema quedaban demasiados versos sueltos que no representaban peligro porque eran débiles política y económicamente, pero cuando la crisis afecte a las exportaciones de café y los paulistas entren en pánico, sacarán las navajas para saldar viejas cuentas. Para ver los pies de barro de todo este sistema basta con echar una ojeada al comercio exterior brasileño.

Sin embargo, a pesar de tener un reducido grado de apertura al exterior, la economía brasileña era muy sensible a los vaivenes externos, en parte por la gran dependencia que había con respecto al café, en parte porque el número de países que consumían café brasileño en cantidades apreciables era muy pequeño dirigiéndose más de la mitad de la producción exportable hacia Estados Unidos, y en parte porque los cafeicultores paulistas y mineiros, en vez de tomar nota de las crisis que se vivieron y controlar la producción para también poder controlar el precio (el Brasil era en estos años el mayor productor mundial con mucha diferencia respecto a los demás ${ }^{8}$ ) se dedicaban alegremente a incrementar el área cultivada con nuevas plantaciones. Los grandes cafeicultores estaban acostumbrados, desde el Convenio de Taubaté de 1906, a que los gobiernos estatales (más exactamente el gobierno de São Paulo) y el gobierno federal compraran excedentes de producción para evitar caídas de precio o para compensar la caída de las exportaciones. Lógicamente esto llevaba a dos situaciones que no eran positivas: Por una parte se hacía girar a la economía brasileña en torno a la producción de café (los productores de azúcar, cacao o caucho no gozaban de estas ventajas) y por otra, como el gobierno no contaba con recursos suficientes para comprar millones de sacas cada vez que estas no tenían salida, había que recurrir a la deuda externa con lo que los créditos que se solicitaban se dedicaban en buena parte a mantener unos precios artificiales en vez de invertirse en actividades más necesarias para el desarrollo del país. Y con ingresos garantizados, los hacendados, no veían la necesidad de frenar el aumento de la producción para mantener unos precios estables en el mercado internacional. Al contrario, tan pronto tenían ocasión, incrementaban la superficie dedicada al cultivo de la rubiácea, así que solo heladas providenciales conseguían compensar el exceso de oferta que, mientras las economías occidentales fueran bien, y singularmente la norteamericana, podía ser absorbida por un creciente consumo, pero cuando entraban en crisis lo que había era un hundimiento inmediato arrastrando tras si el café a toda la economía nacional. Por si fuera poco, desde 1924 la moneda

8 En total, en 1929 había 24 países productores. Mientras que la producción de Brasil era en ese año de algo más de 15.000 .000 de sacas de $60 \mathrm{kgs}$. el resto del mundo no llegaba a los 14.000.000. Esta situación hegemónica se mantendrá hasta 1941 año a partir del cual la producción brasileña, aun siendo la más importante del mundo, estará por debajo de la de los demás países sumados. 
brasileña se mantiene muy fuerte atada al patrón oro con lo cual las exportaciones brasileñas en general se hacían poco competitivas. En resumen, en 1929 estalla la tormenta perfecta. Y no fue porque no se recibieran anuncios.

Se indicó en líneas anteriores que hubo dos supercosechas en 1927 y 1929 en medio de un deterioro de la demanda internacional. Desde 1928 estaban disminuyendo las exportaciones mientras que aumentaban las importaciones, al mismo tiempo estaba reduciéndose el flujo del crédito externo, cada vez más caro y cada vez más difícil de conseguir. En 1929, meses antes del crack, había caído la producción industrial y el PIB tenía un magro incremento del 1,1\% frente al 11\% de promedio del bienio anterior. En los almacenes y depósitos portuarios y en las haciendas se apilaban millones de sacas de café sin salida en una cantidad equivalente a la producción de un año normal. El Instituto del Café, organismo encargado de comprar excedentes, se quedó a comienzos de octubre, sin recursos para adquirir la montaña de sacas sobrantes, los hacendados, que vivían del crédito para mantener su tren de vida, estaban cargados de deudas y no podían exportar y el Banco do Brasil no proporcionaba más préstamos ni facilitaba fondos al Instituto. Y todo esto ocurría antes de que la Bolsa de Nueva York estallara. El mundo, para la oligarquía cafetera, estaba a punto de cambiar radicalmente y todavía no se habían enterado.

En el otro extremo estaba el mundo obrero. Como ya se señaló en su momento, Brasil venía experimentando desde 1914 un creciente aunque limitado desarrollo industrial que se centraba sobre todo en la ciudad de São Paulo. En 1928 había en Brasil 55.164 establecimientos fabriles, aunque llamarle "fábricas" a muchas de estas instalaciones resulta exagerado. Solo el 4,47\% superaba los 12 empleados. Es decir, en su aplastante mayoría se trataba de pequeños talleres e incluso negocios exclusivamente familiares que, como mucho, tenían contratados a dos trabajadores y casi ninguno fuera del círculo familiar. La industria paulista, la más potente con diferencia del Brasil, había superado los 8.000 establecimientos en 1928. La industria textil, por ejemplo contaba con 118 fábricas, bastante por encima del segundo clasificado, Minas Gerais, que tenía 78. Pero esta cifra es engañosa. Las empresas paulistas daban trabajo a 42.930 obreros mientras que las mineiras contaban con 14.155, es decir, tres veces menos, lo que significaba que las industrias de MG eran de menor tamaño. Mientras que en SP había un promedio de 376 trabajadores por fábrica, en MG había 181.

En 1930 el número de obreros urbanos en Brasil ascendía a 428.348 de los que el 27,8\% (119.296) vivían en SP. A pesar del declive de la inmigración, la inmensa mayoría de estos trabajadores continuaba siendo de origen extranjero. En SP predominaban, por este orden, los italianos, los españoles y los portugueses; en el Distrito Federal, los portugueses, lo mismo que en el Nordeste; en Rio Grande do Sul 
el grupo mayoritario era alemán y centroeuropeo (austriaco, húngaro, checo). La crisis del 29 y la caída en picado de la inmigración unidas al hecho de que muchos de estos inmigrantes regresaron a su país de procedencia, hicieron que a lo largo de la década de los 30 la mano de obra nacional fuera sustituyendo a la de origen foráneo. La crisis impactó muy severamente sobre este sector social. A mediados de 1930 el municipio de SP distribuía un promedio de 3.500 comidas diarias a los desempleados. La prensa paulista aireaba cifras de 100.000 parados en el estado aunque las cifras posiblemente sean exageradas. Las empresas aprovecharon la crisis para deshacerse de los trabajadores más combativos y, de paso, bajar los sueldos. Por ejemplo, la "Companhía Santista de Docas" expulsó de un golpe a 1.800 estibadores sindicalizados sustituyéndolos por otros que no lo estaban y que fueron contratados con un $25 \%$ menos de salario. No fue el único caso de limpieza gremial.

Sin embargo esto no nos debe llevar a la conclusión de que el sindicalismo estaba muy extendido. Aunque muy combativos, los sindicatos brasileños de estos años, que eran mayoritariamente anarquistas, no tenían una enorme penetración entre la masa obrera. Muy al contrario. El grado de sindicalización alcanzaba solo al 17\% de los trabajadores industriales y, como eran inmigrantes en su gran mayoría, no se sentían atraídos por la política nacional a la que prestaban escasa atención. Tan escasa que en 1930, y ya en plena crisis, el voto obrero no representó más del 3\% del total emitido en las elecciones de ese año. Todo esto ha llevado a algunos autores a negar la existencia de una auténtica clase proletaria en Brasil. Más bien hablan de un artesanado proletarizado 9 . Y, en cualquier caso, era muy minoritario. En 1930 los trabajadores del sector secundario representaban el 12\% de la mano de obra global frente al 68\% que suponían los efectivos de la mano de obra agrícola. Como clase social, suponiendo que al conjunto de trabajadores industriales les pudiéramos llamar tal, estaba muy aislada lo que impedía una alianza con otros sectores para reivindicar reformas económicas y políticas. Además, los sindicatos de inspiración anarquista no estaban preocupados por la política sino por la situación laboral de sus afiliados (como si ambas cosas estuvieran divorciadas) lo que contribuyó a que el papel de la clase obrera en la revolución de 1930 fuese nulo o, por decirlo suavemente, se limitó a actuar de mero observador desde el tendido. Tendría en el futuro muchas razones para arrepentirse.

La clase media brasileña era escasa y de limitada distribución geográfica. Al ser una clase, igual que el proletariado industrial, típicamente urbana, su presencia se reducía a los núcleos de población, y tan solo en dos tenía presencia significativa: Rio de Janeiro y São Paulo; en las demás ciudades, aunque presente, carecía de peso y de significación política. Basicamente esta clase media urbana estaba integrada

9 V. Teotonio dos Santos (1962). 
por funcionarios, profesiones liberales y pequeños comerciantes y empresarios a los que había que añadir rentistas, militares y trabajadores de cuello blanco que iban desde periodistas a empleados bancarios, contables, profesores etc. Salvo en las dos principales ciudades de Brasil, en el resto era muy dependiente de las oligarquías locales que, al controlar las administraciones públicas, también controlaban los empleos dependientes de ellas lo que hacía que nunca representara un peligro para el poder tradicional. Incluso en São Paulo, en donde suministraron parte de las bases del jovencísimo Partido Demócrata, (PD), una escisión del todopoderoso PRP (Partido Republicano Paulista), nunca llegaron a constituirse en una alternativa política creíble lo que se va a percibir en los vaivenes que da el PD entre 1930 y 1932, primero a favor de Vargas apoyando la revolución de 1930 contra el PRP y después en contra, participando en la revuelta paulista del 32 en connivencia con el perrepismo. Una buena parte de esta clase media era de origen inmigrante.

Además de anémica, la clase media brasileña sufría de fuertes divisiones internas que le impedían crear un frente unido en defensa de sus intereses. Había dos clases de divisiones, una derivada del origen geográfico y otra relacionada con posicionamientos ideológicos. La primera separaba a la clase media de origen nacional de la que procedía de la inmigración. Los brasileños de nación eran muy dependientes del sistema tradicional de poder y poco dados a protestas; se sentían cómodos con el sistema y, si no lo estaban, procuraban acomodarse lo mejor posible; pero los segundos eran más independientes, no se sentían tan vinculados al poder tradicional y defendían reformas políticas entre ellas, una reforma electoral que garantizase la limpieza de los comicios y una representación proporcional a los votos obtenidos. La segunda división separaba a los que solo aspiraban a reformas cosméticas e, incluso, no aspiraban a nada, de los que pretendían un cambio radical del modelo político que incluía un proyecto de nación diferente el cual se podía alcanzar bien por la vía electoral, previas las reformas necesarias, bien por la vía revolucionaria; bien a través de un sistema parlamentario y democrático o bien a través de un régimen dictatorial al cual buena parte de los militares no hacían ascos en aquel momento flirteando como flirteaban, sobre todo la baja y media oficialidad y algunos sectores civiles, con el modelo fascista italiano.

En 1930 una parte destacada de la clase media se había liberado de la serie de prejuicios heredados de la oligarquía: La pacata preocupación por las apariencias, el culto a la etiqueta etc. De lo que no se había librado ni se libraría en el futuro sería de su anhelo de ascender económicamente acompañado de una casi delirante persecución de los signos de identidad del triunfador social: Tener coche, vivir en apartamentos de las zonas residenciales, enviar a los hijos a los colegios privados... En definitiva, se trataba de un proceso de mimetización colectiva con las formas de vida de la odiada/envidiada/admirada clase alta. En 1930 todo esto está aún en 
sus comienzos, pero en los años siguientes el proceso se va a acelerar a una enorme velocidad. Cuando Vargas cae en 1945 la clase media se había consolidado como el eje en torno al cual giraba la vida política, cultural y económica del país.

\section{La crisis y algo parecido a una revolución}

A pesar de que en 1930 los efectos del crack de la Bolsa de Nueva York eran más que visibles y la economía brasileña estaba ya atravesando una situación de caída libre, no será la ruina de los cafeicultores ni el galopante desempleo lo que cause la revuelta. Lo que permite que hubiera una llamémosle revolución por llamarle algo, es la ruptura de la alianza oligárquica mineiro-paulista. Fue la crisis política de la sucesión presidencial la que dio alas a los deseos de reforma de las oligarquías periféricas las cuales no deseaban otra cosa que participar del juego político con un mayor protagonismo. El problema fue que, una vez abierto el boquete, la herrumbrosa construcción de la república oligárquica, cuyos cimientos estaban sometidos a una fortísima presión a los largo de los años 20 (huelgas obreras, revueltas militares etc.) se vino abajo si no completamente, sí en buena parte. En el futuro la oligarquía agraria ya no ejercería en solitario el poder. Tendría que compartirlo (y a veces aceptar solo las migajas que otros le daban) con nuevos protagonistas sociales: Clases medias, militares, intelectuales, sindicatos de trabajadores etc. El escenario, de pronto, se había llenado de personajes y personajillos todos con ansias de actuar en la primera línea. El laboratorio en el que se urdió toda la trama no podía prever el cambio histórico que se iba a producir pero es que, aunque fue un grupo de golpistas el que puso en marcha el proceso, nada hubiera ocurrido sin que, para espanto de las élites, las masas urbanas no hubieran pasado a protagonizar los acontecimientos.

En Iberoamérica se ha usado y abusado de la palabra "revolución”. Si pensamos en un concepto de revolución en el que mediante el empleo de la violencia a gran escala se consigue cambiar radicalmente una etapa histórica para sustituirla por otra al estilo de lo que ocurrió con la Revolución Francesa o la Revolución Rusa o en menor grado con la Revolución Inglesa o la Comuna de París, en Iberoamérica nos encontramos con tres situaciones auténticamente revolucionarias que marcan un antes y un después: La revolución de la Independencia, la Revolución Mexicana y la Revolución Cubana ${ }^{10}$. Todo lo demás fueron movimientos armados que

10 Se podía hablar de la Revolución Sandinista pero esta, $1^{\circ}$ duró poco, $2^{\circ}$ no dejó de ser un epígono en la estela de la Revolución Cubana y $3^{\circ}$ alguno de sus protagonistas más importantes hoy ejerce el poder en el país de un modo que recuerda mucho a Somoza, el entonces tirano. 
enfrentaban a fracciones de la élite dominante pero que non alteraban para nada el status quo social y económico (prácticamente ni el político a menos que consideremos como "revolucionario" políticamente la doctrina del quítate tú que me pongo yo).

¿Y qué ocurre en Brasil? Muchos historiadores han negado el carácter revolucionario de los acontecimientos de 1930, para empezar los historiadores e intelectuales de filiación marxista para muchos de los cuales no hay revolución posible sin la presencia y el protagonismo de la clase trabajadora. Y, ciertamente, la clase trabajadora brasileña brilló por su ausencia ese año. Pero también es cierto que los obreros no son los únicos protagonistas de la historia (mal que le pese a Lenin), ni siquiera para hacer una revolución como muchos ejemplos muestran. No son los trabajadores de Brasil los que quitan o ponen revoluciones, no fueron tampoco los protagonistas de 1930 los que dieron carácter revolucionario a lo acontecido, nada más lejos de su intención por otra parte. Conviene no olvidarse que, cuando la oligarquía mineira se suma a la revuelta habla claramente de "revolución conservadora" lo que da una idea clara de lo que pensaban sobre lo que estaba sucediendo. Nada peligroso para el poder tradicional. Pero resulta que lo fue. No en aquel momento pero si en los años sucesivos. Lo revolucionario no fue deponer a Washington Luis, lo revolucionario vino después cuando, como ya indiqué antes, se abrieron las compuertas por las que entraron nuevos protagonistas. Y entraron para quedarse. Y eso a pesar de que, como ocurre casi siempre en estos casos, los aprendices de brujo empezaron prometiendo todo tipo de reformas democráticas, luego desconfiaron del uso social que podían darle a las libertades las masas no controladas, a continuación pasaron a limitarlas argumentado las condiciones especiales que se vivían y acabaron por imponer una dictadura. Fue justamente eso lo que representó el RIP de lo que se pretendía conservar.

Vayamos a los hechos.

La crisis política que llevaría al final de la Primera República fue consecuencia del choque entre mineiros y paulistas por la sucesión presidencial. Como ya se indicó anteriormente el pacto del café con leche marcaba una alternancia en el ejercicio de la presidencia de la República entre representantes de las dos oligarquías más importantes y poderosas del país. Mal que bien, tal alternancia se había mantenido a los largo de 30 años. De acuerdo al pacto, a un presidente paulista, Washington Luis, debería suceder un presidente mineiro. Pero resulta que no fue así. El jefe del Estado tenía a su propio tapado, el también paulista Júlio Prestes, ganador de unas elecciones fraudulentas como era habitual. Probablemente el PRM (Partido Republicano Mineiro) hubiera tragado bilis en otras circunstancias. Pero el panorama había cambiado en tres meses de manera acelerada y sin marcha atrás y las circunstancias eran otras. Llegó un momento en que al PRM solo le quedaban 
dos alternativas: Ser barrido de la escena como le iba a ocurrir al PRP o subirse al carro de la revolución. Y tal como venía la mano prefirió subirse al carro.

Los hechos que iban a desembocar en una revolución política comenzaron en junio de 1928. En esas fechas, y a dos años de las elecciones, la prensa paulista y carioca estaba inmersa en el gran debate de la sucesión cuando comenzaba a verse claro que el candidato oficial no venía de Minas Gerais ${ }^{11}$. Este debate sacaba a la luz un hecho preocupante: el frente oligárquico estaba con hendiduras de difícil solución. Y al vicepresidente de Rio Grande do Sul, João Neves da Fontoura, se le ocurrió pensar que, aprovechando la coyuntura, había llegado el momento de que hubiera un presidente gaúcho. Y así se lo propuso a Getúlio Vargas casi recién posesionado del cargo de presidente del estado. Vargas era un hombre de reacciones lentas, pausadas, pensadas y repensadas. Dio largas al asunto pero no se opuso a la idea.

El candidato oficialista era gobernador de São Paulo y su designación no encontró la oposición de los gobernadores salvo los de tres estados: Minas Gerais, Rio Grande do Sul y Paraíba. Este último era pequeño y pesaba poco, pero Minas era el fiel de la balanza en la política nacional y Rio Grande do Sul era un estado emergente a todos los efectos y con una gran tradición revolucionaría detrás.

Los mentideros políticos y las redacciones de periódicos de Rio de Janeiro y São Paulo eran, desde comienzos de 1929, un hervidero de rumores apuntando todos a que en Porto Alegre (capital de RGdoS) se estaba preparando algo. De hecho, ante el rechazo que la candidatura de Júlio Prestes provocaba en un amplio sector del PRM, se decía que el presidente estaba pensando en proponer a Vargas como candidato de consenso para calmar a Minas Gerais. No hubo tal y la candidatura de Prestes siguió adelante. Entretanto en Porto Alegre, tras un año de conversaciones, negociaciones, encuentros, avances y retrocesos, en agosto de 1929 se anunciaba la candidatura oficial de Vargas a la presidencia y del presidente de Paraíba João Pessoa a la vicepresidencia. En la alianza electoral entraban el Partido Republicano de Paraíba, el Partido Democrático de São Paulo, el Partido Libertador de Rio Grande do Sul, una parte del PRM y otras agrupaciones menores además de apoyos externos que incluían al oficialato bajo y medio y a parte del clero. Este conglomerado se llamó Aliança Liberal (AL) y su discurso no representaba ningún cambio radical en campo alguno con respecto al oficialismo. Se hacía sobre todo incidencia en la moralización de la vida pública, en el final de la corrupción administrativa y se hacía una llamada a las periferias para reaccionar frente a la hegemonía paulista. Aparecía así la AL como una plataforma de excluidos que reivindicaban su derecho a participar en la vida pública de manera significativa.

11 Así opina João de Lira Neto en su monumental biografía de Getúlio Vargas en 3 Vol. Lira Neto (2012), Vol. I, pg. 277. 
La campaña electoral polarizó a la prensa y a la opinión pública urbana que era la que votaba. Tuvo una intensidad como no se recordaba desde los comicios de 1910. Y, como estaba previsto, en las elecciones celebradas el 1 de marzo de 1930, sábado de carnaval, ganó el candidato oficialista por 1.091 .709 sufragios frente a los 742.794 conseguidos por el tándem Vargas-Pessoa. Vargas, hombre del sistema al fin y al cabo, estaba en disposición de aceptar los resultados pero la situación se volvió explosiva en muy poco tiempo. En primer lugar comenzaron a llegar denuncias de fraude que se hacían públicas en los diarios opositores un día sí y otro también alimentando una atmósfera de desconfianza cuando la crisis económica estaba golpeando muy duramente a Brasil; en segundo lugar en el puerto de Santos se apilaban 14 millones de sacas de café que no tenían salida mientras que el cosechón de ese año amenazaba con incrementar los stocks en 25 millones más, el gobierno de São Paulo necesitaba urgentemente millón y medio de cuentos ${ }^{12}$ para poder adquirir semejante cantidad de excedentes pero ni disponía de esos recursos ni podía acudir al endeudamiento pues los mercados financieros de Nueva York y Londres no prestaban dinero. El candidato Prestes, proclamado vencedor de la elección por el parlamento federal y, por tanto, presidente legítimo, se embarcó hacia Estados Unidos y Europa para darse a conocer y negociar posibles créditos. Y mientras viajaba, en Brasil estallaba la tormenta.

En RGdoS se estaban preparando para lo peor, y lo peor era una revuelta armada a la que Vargas se oponía pero a la que no le quedó más remedio que encabezar cuando su compañero de candidatura fue asesinado en una pastelería de Recife. El crimen tenía como trasfondo un sórdido "affaire" amoroso, pero en Rio la prensa opositora lo presentó como un crimen político y Pessoa fue de inmediato elevado a la categoría de mártir revolucionario, algo que estaba muy lejos de ser. Ante los hechos consumados a Vargas no le quedó otra que encabezar un movimiento armado contra el gobierno de Washington Luis. El 3 de octubre RGdoS iniciaba la revolución.

En el escenario de enfrentamiento que se abría podríamos hablar de tres círculos de alianzas. El primero está compuesto por el bloque de poder PRP-PRM (solo en parte) con el apoyo social de la mayor parte de los hacendados paulistas y mineiros, la gran empresa y el mundo de las finanzas siempre alérgicos a algaradas que se saben cómo comienzan pero no cómo terminan, y una fracción, la más conservadora, de la clase media paulista. El segundo círculo era el revolucionario en el que aparecían aliados elementos heterogéneos y de intereses contradictorios. Estaba integrado por los que habían participado en la AL más una parte importante del ejército en la que abundaban sargentos, tenientes y capitanes y escaseaban

12 Un cuento equivale a mil mil-reis. 
coroneles y generales, y la mayoría de la clase media urbana que acaba arrastrando el apoyo de los gobiernos del nordeste a los cuales se les estaba brindando en bandeja la oportunidad de recuperar su influencia sobre el gobierno central. El tercer círculo es el de los ausentes: El campesinado, completamente al margen de todo aquel conflicto y la clase obrera que, o bien por su origen inmigrante aquello ni le iba ni le venía, o bien por su adscripción a sindicatos anarquistas y comunistas, negaban cualquier carácter de revolución a lo que estaba sucediendo y solo percibían el movimiento como un conflicto intraoligárquico del que lo único que se podía esperar, ganara quien ganase, era más de lo mismo. Los dos primeros círculos estaban relacionados entre sí por motivos de confrontación, pero el tercero era ajeno. La revolución fue, por lo tanto, un fenómeno urbano y mesocrático. Y eso estaba reflejando cambios profundos en la base social de la política nacional.

Sin embargo el frente unido contra el gobierno federal tenía una debilidad que, una vez triunfante la revolución, sería demasiado evidente. Esa debilidad era consecuencia no solo de lo heterogéneo de los integrantes sino, y sobre todo, de sus intereses contradictorios: La fracción del PRM que apoya a Vargas formaba parte de la oligarquía tradicional, lo mismo que el propio Vargas y todo el PL, y lo mismo se podía decir de los diversos aportes nordestinos. Para todos ellos se trataba de una revolución conservadora nacida de aquella parte de las élites que se autoconsideraba regeneracionista entendiendo por regeneracionismo acabar con la alianza del café con leche y abrir el gobierno a la participación de las oligarquías periféricas que, a su vez, también mantenían fuertes diferencias entre ellas. Mientras que el Nordeste continuaba apoyándose en la producción de cacao, azúcar y ganado, actividades, especialmente el azúcar, que estaban en decadencia continuada desde el S.XVIII, Rio Grande do Sul era un estado emergente, poco perjudicado por la crisis económica en la medida en que su producción, ganado y yerba mate, se dedicaba al consumo interno. La producción de charque o carne seca que ya venía desarrollándose desde el S.XIX, tenía un mercado seguro, la población de menos recursos ya que se trataba de un alimento barato. Los hacendados gaúchos no atravesaban una situación de ruina similar a la de sus congéneres de São Paulo por lo tanto estaban en mejores condiciones para reclamar su parte del pastel. Tampoco estaban endeudados, pues lejos, de las magnificencias los cafeicultores, llevaban una vida bastante frugal. Después de comer asado, beber mate y holgar si se presentaba la ocasión, no había nada que gustase más a las élites locales que hacer una revolución de vez en cuando. Montarse a caballo, tirarse al monte poncho en ristre y organizar patriadas eran el supremo deleite, igual que ocurría con sus parientes, amigos y vecinos del Uruguay. No olvidemos que en el S.XIX Rio Grande do Sul llegó a constituir por unos años un estado independiente conocido como República Riograndense a favor de la cual luchó Garibaldi antes de iniciar su movi- 
miento armado en Italia ${ }^{13}$. El problema de los centauros gaúchos es que tenían una mentalidad demasiado doméstica, es decir, si traspasaban las fronteras del estado se consideraban ya en el extranjero. Estaban prontos a dar la vida por sus ideas y su regionalismo, pero siempre y cuando eso no supusiera dar un paso más allá de los límites de su demarcación. Con semejantes revolucionarios era difícil pensar en llevar la lucha hasta Rio de Janeiro por lo que el principal apoyo de Vargas vino de la policía riograndense y del ejército que eran cuerpos disciplinados.

La oficialidad revolucionaria, que tenía una larga experiencia en organizar movimientos subversivos en la década anterior, había construido una imagen del Estado que no tenía nada que ver con lo que era la idea dominante en el Brasil. En primer lugar era anti federalista porque pensaba que el federalismo debilitaba al Estado al crear poderes paralelos. La Nación tenía que ser una y el Estado tenía que ser uno, fuerte e intervencionista en todos los campos. En segundo lugar era antiliberal, no creían para nada en la democracia a la que consideraban una fuente de corrupción y división, negando cualquier valor al voto. Un gobierno nacional tenía que ser autoritario e integrado por élites, no económicas, sino intelectuales, aquellas que se definían como claramente nacionalistas y fueran anti cosmopolitas. En tercer lugar era industrialista y desarrollista. Un país de base agraria solo podía ser un país atrasado y todavía peor si en la mesa no se ponía ni el primer plato, ni el segundo plato, ni siquiera el postre. Solo el café y el azúcar. Lógicamente ante la carencia de capitales domésticos interesados en invertir en la industria, el Estado tenía que actuar como promotor a través de empresas públicas. En cuarto lugar los militares no estaban en contra de la inmigración siempre que los inmigrantes se nacionalizaran rápidamente y pasaran a hablar portugués así como enviar a sus hijos a una escuela unificadora que transmitiera valores patrióticos. Nada de prensa, emisiones de radio, asociaciones, colegios o actividades religiosas que utilizaran las lenguas de los países de origen.

El PD, el partido que representaba a fracciones de la clase media y del empresariado comercial e industrial paulista, era exactamente todo lo contrario comenzando por su anti industrialismo lo que no dejaba de ser paradójico teniendo en cuenta con qué apoyo contaban. De la reforma del Estado solo aspiraba a ampliar la base electoral y a garantizar la limpieza del voto. Pretendía una ampliación en la participación política de los ciudadanos, no restricciones ni limitaciones. Y desde luego era civilista y muy paulista con lo cual los discursos anti federalistas caían muy mal en el partido.

13 Garibaldi participó también en la creación de la brevísima República Juliana cuyo territorio era el del actual estado de Santa Catarina, vecino con RGdoS. En medio de todas estas aventuras Garibaldi conoció y se unió a Ana María de Jesús Ribero, Anita Garibaldi, conocida como la heroína de dos mundos. 
Pero mientras la coalición se mantuvo Vargas pudo vencer, no sin una importante aportación de muertos. El 24 de octubre Washington Luis era derrocado, encerrado en una prisión militar y luego enviado al exilio en Portugal. El 31 Getúlio hacía su entrada triunfal y multitudinaria en Rio de Janeiro. Aunque de manera figurada, los gaúchos habían atado sus caballos en las farolas de Copacabana. Así había sido la revolución de 1930. ¿Acabada? No, la revolución, sin que sus participantes se dieran cuenta, no había hecho más que empezar.

\section{A modo de conclusiones}

¿Que tienen de revolucionarios los acontecimientos de 1930? Si la revuelta de octubre se hubiera quedado en un simple cambio de mandatarios, lo ocurrido en Brasil no tendría otro significado que el de una exitosa algarada armada. De ese tipo hubo unas cuantas en Iberoamérica a lo largo de la década: República Dominicana (1930), Argentina (1930), El Salvador (1931), Bolivia (1936 y 1939), Ecuador (1931, 1932, 1934, 1937), Perú (1930, 1931), Chile (1931, 1932), Uruguay (1933), Panamá (1931), Nicaragua (1936), Cuba (1933), Paraguay (1936, 1937). Un rico panorama de inestabilidades diversas que dan salida a múltiples experiencias liberales, dictatoriales, conservadoras y hasta socialistas. Golpes de estado militar, autogolpes, golpes de inspiración oligárquica, establecimiento de dictaduras dinásticas y caudillajes de larga duración etc. Hubo de todo. Pero el número de las que merecen el adjetivo de revolucionarias es muy limitado. La de Brasil es una de ellos.

En un primer momento la revuelta de 1930 no parece otra cosa más que un reajuste en el reparto del poder dentro de la fracción oligárquica. Y, de hecho, Vargas no accede a la presidencia con la intención de volverlo todo del revés. Muy por el contrario. Hizo lo posible y lo imposible por salvar los muebles del sistema. Pero se encontró con tres escenarios contradictorios que ponían en peligro su triunfo. En el primero se mueve la oligarquía paulista que, aunque alejada del poder, no se consideraba vencida y no estaba dispuesta a compartir el poder con advenedizos. Esa oligarquía manifiesta su oposición al gobierno a través de tres vías: La exigencia de un interventor civil y paulista ${ }^{14}$, la reivindicación de un gobierno constitu-

14 El gobierno nacido de la revolución, aunque no suspende el sistema federal, nombra a interventores para sustituir a los gobernadores que, salvo en el caso de Minas Gerais, son todos destituidos. Algunos de estos interventores eran militares. A São Paulo le tocó un militar profundamente centralista y originario de Pernambuco. Los paulistas vieron aquel gesto como la imposición de un gobierno de ocupación y reaccionaron airadamente. La crisis se extendió cuando el PD, aliado hasta entonces de Vargas, pasa a la oposición al ser desairado pues aspiraba a que la intendencia fuese para su líder. 
cional y legítimo ${ }^{15}$ y los escarceos con el separatismo que era alentado por ciertos sectores intelectuales ligados al PRP. Pero por otra parte para los hacendados, que necesitaban con urgencia la ayuda del Gobierno central para comprar los millones de sacas que se amontonaban en Santos sin perspectivas de salida y con la amenaza de incrementarse todavía más, se imponía algún tipo de diálogo. Al final las emociones y la imagen de la Paulicea humillada a partes iguales por gaúchos, militares y nordestinos, llevó a un choque armado: La guerra paulista de 1932, a la que se arrojaron alegremente sin medir ni consecuencias ni posibilidades, le dio la estocada al poder oligárquico tradicional. Por ese lado Vargas eliminó a un sector peligroso que, por miedo y por quedar decapitado, dejó de ser una amenaza por mucho tiempo. Hasta la apertura del proceso democratizador en 1945, la oligarquía tradicional no volvió a levantar cabeza.

En el segundo se mueve el movimiento obrero en el que los comunistas sustituyen a los anarquistas al frente de los sindicatos. Y de la no participación en los acontecimientos de 1930 algo se había aprendido, siendo el primer aprendizaje que la clase trabajadora no podía estar al margen de los acontecimientos políticos. Entre muchos intelectuales el marxismo se había puesto de moda y la nueva táctica de frentes populares inspirada desde Moscú consiguió unificar en un gran frente partidario, la ANL (Aliança Nacional Libertadora), a comunistas, socialistas, demócratas progresistas y a algunos militares. En 1935 se intentó un golpe de estado en un movimiento muy mal coordinado (al parecer inducido desde el propio gobierno pues la ANL estaba trufada de infiltrados y agentes provocadores) que acabó en otro desastre. La derrota de las fuerzas progresistas le sirvió a Vargas para limpiar el campo por su izquierda al mismo tiempo que amenazaba con más peligros comunistas a un aterrado Parlamento en el que abundaban los grandes propietarios.

El tercer escenario era el militar y ese sí que resultaba peligroso. La oficialidad no había apoyado a Vargas desinteresadamente. En el movimiento de 1930 vieron una oportunidad para imponer sus puntos de vista: Centralismo, modernización, disciplina y gobierno autoritario. Vargas era un federalista convencido pero comenzó a flirtear abiertamente con el fortalecimiento del poder central a costa de los estados a partir de la guerra paulista que se había ganado en buena medida porque la mayor parte de las Fuerzas Armadas reaccionaron contra la amenaza de romper el país. Los militares, después de la experiencia de 1932, no estaban por la labor de reinstaurar un nuevo pacto de estados como había ocurrido con

15 La defensa de la constitución de la Primera República no tenía otro sentido que garantizar la vuelta del poder cafeicultor pero como esto no se podía reconocer, se clamaba por reimplantar la legalidad tachando al gobierno provisional de dictadura. 
la Primera República. La modernización, a su vez, pasaba por la industrialización y esto suponía desviar fondos del gobierno para incentivar las inversiones fabriles estratégicas (la siderurgia, por ejemplo) en perjuicio de las subvenciones que recibían los cafeicultores al garantizarles precios mínimos. Pero modernizar era también crear nación. Hasta entonces la idea de nación en Brasil no había tenido mucho éxito. Al no estar extendida una educación pública que unificara a través de un discurso común la formación de los jóvenes, una buena parte de los brasileños no sabía de lo que hablaba cuando hablaba de Brasil. Realidades inmensas como la Amazonia, Mato Grosso, el Norte, el Oeste, eran absolutamente ajenas a los habitantes de las ciudades de la costa para quienes el país quedaba reducido a lo que entendían por país útil, es decir el litoral que desde el Nordeste llegaba hasta el sur en una franja que no iba más allá de 200 kms. tierra adentro. Tan poco conciencia había de lo que era una nación que el único partido "nacional" existente en 1930 era el Partido Comunista y todos sus afiliados cabían, por aquellos años, en 4 vagones de un tren. A decir verdad, las FFAA eran, junto a la Iglesia Católica, presente en cualquier rincón, las únicas instituciones que tenían una imagen completa de la realidad del país. Los oficiales destinados en guarniciones lejanísimas que recibían soldados en gran parte analfabetos y desnutridos para los que el concepto de patria era practicamente incomprensible, y los misioneros que trabajaban en zonas a donde no llegaban más que ellos, sí conocían el rostro auténtico del país. Los políticos de Rio, para quien la mayor parte de Brasil no pasaba de ser más que una representación cartográfica, no. Por último los militares eran conscientes de que Brasil era, en términos poblacionales, la olla del cocido: Negros, indios, mulatos, mestizos, blancos originarios de múltiples países, hablando lenguas distintas y rezando a dioses diferentes, asiáticos, judíos, árabes... Crear una nación con valores compartidos ante tal diversidad solo era posible imponiendo la portuguesización a las bravas y una disciplina social que en un sistema liberal-democrático no parecía posible. De ahí que la única salida que hiciera esto realizable, y lo llevara a cabo aceleradamente, era imponiendo un régimen autoritario. En 1937 la situación ya estaba madura para que los militares decidieran aplicar sus puntos de vista alentados, además, por lo que estaba sucediendo en Europa en donde florecían los gobiernos totalitarios que aparecían como ejemplo de modernización y movilización social en torno a unos ideales patrióticos y políticos impuestos a la fuerza. Vargas lo vio venir. O se ponía al frente del golpe o el golpe le pasaba por encima. Así que agarró la pancarta. El autogolpe de estado de 1937 que marca el inicio del llamado Estado Novo, siguiendo la terminología del régimen salazarista de Portugal, marca también el fin de un periodo de transición entre la crisis del estado oligárquico (feudal en terminología marxista) y el nacimiento de un nuevo modelo de estado burgués (en la misma terminolo- 
gía) más intervencionista y al que las clases medias urbanas, la clase obrera y el empresariado no agrícola no tardarían en incorporarse a través de las diversas plataformas sociales y partidarias que en los años siguientes se irían creando. Esto, y no otra cosa, fue lo que tuvo de revolucionario el proceso iniciado en 1930 que comienza como una algarada tradicional y acabó creando el Brasil moderno. 


\section{Bibliografía}

Camargo, A. (1973): Brésil, Nord-Est: Mouvements paysans et crise populiste. Paris, École Pratique des Hautes Etudes. Tesis Doctoral mimeografiada. Esta tesis nunca llegó a ser publicada en su totalidad pero amplios fragmentos de la misma aparecen en trabajos posteriores de la autora.

De Paiva Abreu, M. (coord.) (1989): A ordem do progresso. Cem anos de política econômica republicana (1889-1989). Rio de Janeiro, Ed. Campusç.

Furtado, C. (1969): La economía latinoamericana desde la conquista ibérica hasta la revolución cubana. México, Siglo XXI Ed.

González Casanova, P. (1965): La Democracia en México. México, Ed. Era.

González Casanova, P. (Coord.) (1977): América Latina en los años Treinta. México, UNAM.

Lira Neto, João de (2012): Getúlio, Vol. I. São Paulo, Companhia das Letras.

Maddison, Angus (1988): Dos crisis, América Latina y Asia, 1929-1938 y 1973-1983. México, FCE.

Santos, T. dos (1962): O movimento operário no Brasil. Revista Brasiliense, 39.

Sixirei, C. (1988): El Brasil de Vargas, Vol.I, Madrid, Universidad Complutense.

Sixirei, C. (2019): Plaza del Mundo. Madrid, Ed. Verbum.

Taleb, N.N. (2008): El cisne negro. El impacto de lo altamente improbable. Barcelona, Ed. Paidós Ibérica. 
